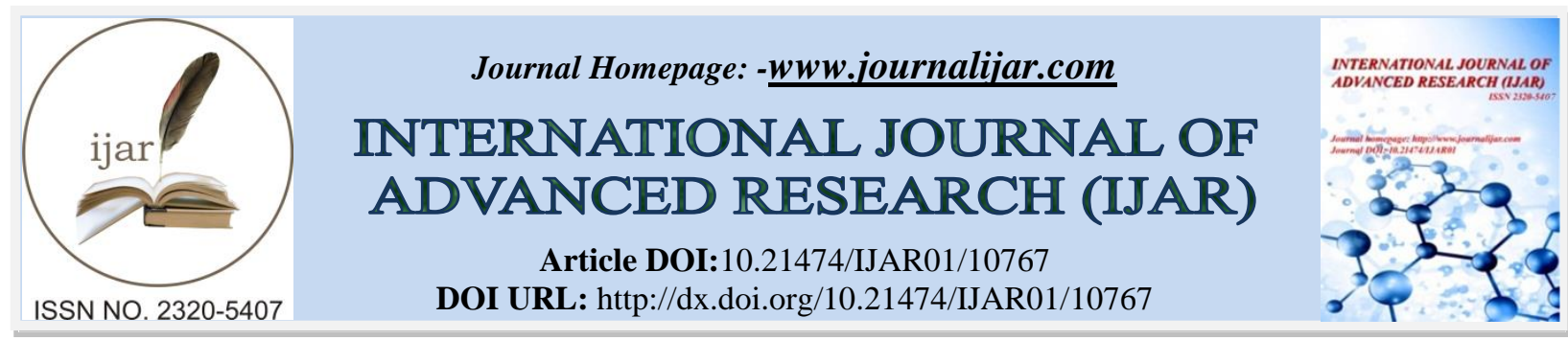

RESEARCH ARTICLE

\title{
COMPARING MAXIMUM BITE FORCE FOR DIABETIC PATIENTS WEARING TWO DIFFERENT TYPES OF REMOVABLE PARTIAL DENTURES: A RANDOMIZED CROSS-OVER STUDY
}

Eman Mostafa Ahmed Ibraheem and Ahmed Mostafa Esmat El-sisy

\section{Manuscript Info}

\section{Manuscript History}

Received: 07 February 2020

Final Accepted: 10 March 2020

Published: April 2020

Key words:-

Maximum Bite Force, Heat Cure Acrylic Denture, Flexible Partial Dentures, Bounded Posterior Partial Denture, Diabetic Patients

\begin{abstract}
Objective: This study was carried out to compare themaximum bite Force of diabetic patients wearing two different types of removable partial dentures; heat cured acrylic and flexible denture base. The patients were controlled type 2 diabetes mellitus patients(T2DM) having maxillary and mandibular bounded posterior edentulous span (Class III Kennedy classification) opposing each other during different time intervals.

Materials and Methods: thirty controlled type 2 diabetic patient having maxillary and mandibular posterior bounded edentulous span (Class III Kennedy classification) opposing each other were selected. Maximum bite forces (MBF) were measured for both polymethyl methacrylateheat cure resin (PMMA) and thermoplastic acrylic removablepartial denture by using a portable force gauge. Records were taken one day after delivery, one month and 2 months later for each partial denture.

Results: MBF for thermoplastic denture was significantly higher than PMMA denture $(\mathrm{P}<0.05)$ as in PMMA denture it was $(27.2 \pm 3.8,30.6$ $\pm 4.04,35.4 \pm 4.7)$ while in thermoplastic denture it was $(55.4 \pm 5.9$, $60.2 \pm 4.1 \& 67.6 \pm 5.1)$ after delivery, one month and 2 months later respectively.

Conclusion: The thermoplastic acrylic partial dentures showed higher maximum bite force than the polymethyl methacrylate heat cure acrylic partial dentures in all recorded time intervals and the maximum bite force was increased in both dentures with increasing the adaptation period.
\end{abstract}

Copy Right, IJAR, 2020,. All rights reserved.

\section{Introduction: -}

Removable partial denture (RPD) used for rehabilitation of lost natural dentition aims to restore patient's masticatory function, speech and esthetics. However partial dentures have less masticatory presentation, bite force than natural dentition about one half to one sixth those of dentate patients, depending on denture type and site and numbers of missing teeth ${ }^{(1-3)}$

Bite force can be defined as "the force applied by the masticatory muscles in dental occlusion". Bite force is produced by the interaction of the muscles of mastication, the maxillae and mandibles, the temporomandibular joints (TMJs), and natural or artificial teeth ${ }^{(4)}$

Corresponding Author:- Ahmed Mostafa Esmat El-sisy 
Bite force can evaluate the efficacy and function of the stomatognathic system, efficacy of dental prosthesis, or to study effects of defects like malocclusion on the masticatory system and temporomandibular disorders $(5,6)$.

The devices that measure bite force are mechanical or electrical or both together. The former devices, were mechanical called as gnathodynamometer. In this device weightsup to $200 \mathrm{~kg}$ were attached to a cord over the mandibular posterior teeth in open mouth position, then patients were asked to close ${ }^{(7)}$.

Nowadays, highly sensitive electronic devices are used to measure the bite force. Recent devices givesmore precise load measurement.Recent devices can record a force ranged from 50 to $800 \mathrm{~N}$ with accurateness $10 \mathrm{~N}$ and exactness $80 \%$. These devices use transducers (load cells) to convert force into electrical energy. Types of load cells (force transducers) are strain-gauge transducers, piezoelectric transducers and pressure transducers ${ }^{(8)}$.

Strain-gauge transducers provides accurate measurement of maximum bite force, despite is still difficult to measure the true maximum bite force due to the possibility of cuspal breaking of teeth and dental prosthesis when biting on the hard transducers ${ }^{(8)}$.

When force is exerted, crystalline material (like quartz) gives charges that is directly proportionate to the degree of force change. The crystals are called as piezoelectric crystals ${ }^{(9)}$.

The pressure transducers comprise a chamber filled with air or fluid. The pressure inside the chamber increases as force is exerted. The increased pressure transferred to pressure gauge for recording. The pressure transducers can be either pneumatic (contain air) and hydraulic (contain liquid) $)^{(10)}$.

Somecommercially available devices for recording bite force are such as Dentoforce 2 (ITL AB, Sollentuna, Sweden), IDDK (Kratos, Cotia, São Paulo, Brazil), GM10 (Nagano Keiki, Japan), T Scan system (Tekscan, Inc., South Boston, MA),Prescale system (GC Co. Ltd, Japan), MPX 5700 (Motorola, SPS, Austin, TX, USA), FSR No. 151 (Interlink Electronics Inc., Camarillo, CA, USA), MPM -3000 (Nihon, Koudenshi Co, Tokyo) and Flexiforce (Tekscan, South Boston, MA, USA) $)^{(11) .}$

Several factors can impact the recording of bite force such as craniofacial morphology, sex, age, periodontal condition, number and position of missing teeth, number and position of opposing teeth, type of dental prosthesis, neuromuscular disease, temporomandibular disorders (TMDs) and the type of measuring devices ${ }^{(12) .}$

Polymethyl methacrylate (PMMA) is the most commonly used material for fabrication ofdental prostheses. PMMAprovides good aesthetic demands and sufficient mechanical requirements of prosthesis. PMMA as many disadvantages such as difficult insertion in undercuts, brittleness which leads to its easy fracture, and allergy to residual monomer ${ }^{(13,14)}$.

Thermoplastic dental materials (Valplastand Flexite) belongs to polyamides group and were used for dental applications (nylon plastics) ${ }^{(15)}$.

Flexible dentures are an excellent alternate to PMMA dentures, as they have several advantages over the rigid PMMA denture bases, translucencyand no clasping provides better esthetics, biocompatibility due to absence of free monomer, strong make it can be processed in thin sections, flexible behavior in undercut areas and flexible dentures that are fabricated by the injection molded technique exhibit better accuracy compared to PMMA ${ }^{(16,17) .}$

The injection molded thermoplastic resins had less modulus of elasticity, lesser flexural strength and similar orhigherimpact strength than PMMA ${ }^{(18)}$.

Diabetes mellitus (DM) is glucose, fat \& protein metabolismdisturbance due toreducedsecretion of insulin, resistance to insulin or both. DM was classified into type 1, type 2, hybrid forms, unclassified diabetes and hyperglycemia first detected during pregnancy. Type 2 diabetes (T2DM) accounts for $90 \%-95 \%$ of diabetes (WHO, 2019).The most clinically important metabolic deviation in diabetesmellitus is hyperglycemia. Long term hyperglycemia are associated with multiple complications such asrenal, cardiovascular, ophthalmic, cerebrovascular $\&$ peripheral neurological disorders ${ }^{(19)}$. 
T2DM is associated with macro- and micro-vascular complications. Diabetic patients are more likely suffering of xerostomia (dry mouth) than non-diabetic ones. Also they have periodontal problems, caries, multiple teeth loss and they need continuous prosthetic adjustments ${ }^{(20)}$.

\section{Objective of Research:-}

This study aimed to compare the maximum bite force of diabetic patients wearing two different types of removable partial dentures; heat cured acrylic and flexible denture base.

\section{Materials and Methods:- \\ Ethical considerations:}

At beginning of the study, patient's data (personal, medical, and dental) were collected according to theimplemented principles of research ethical committeeofthe National Research Centre (NRC), and written consents were obtained from the participating patients. All patients were informed about practical steps of this study and signed approval consent. This study was approved by the Ethics Committee of National Research Centre (Approval No. 16/086).

\section{Materials:}

Heat-cure acrylic resin was obtained from AcrostoneDental \& Medical Supplies.

Nylon

(bre.flex2,http://www.eschoenitz.co.uk/wpcontent/uploads/2019/02/thermopress-400_000626GB20180119.pdf)

\section{Patients:}

Thirty diabetic patient having maxillary and mandibular posterior bounded edentulous span (Class III Kennedy classification) opposing each other were selected.

Polymethyl methacrylate heat cure resin (PMMA) removable partial dentures were fabricated for each patient. Bite forces were measured by using a portable force gauge. Records were taken one day after delivery, one month and two months later after wearing PMMA partial denture.

Then thermoplastic acrylicremovable partial dentures were fabricated for each patient. Bite forces were measured by using a portable force gauge. Records were taken one day after delivery, one month and two months later after wearingthermoplastic partial denture.

\section{Inclusion criteria:}

1. All patients having maxillary and mandibular posterior bounded edentulous span (Class III Kennedy classification) opposing each.

2. Age range 45 to 55 were enrolled.

3. No previous partial dentures experience.

4. Well-developed edentulous ridges covered with firm mucoperiostia.

5. Nonsmokers.

6. Skeletally Angle's class I.

7. All patients were controlled type 2 diabetics for not more than 5 years(i.e. fasting serum glucose level was higher than $126 \mathrm{mg} / \mathrm{dl}$ as well as the level of glycosylated hemoglobin (HbA1c) does not exceed 7.5\% during the whole study period).

\section{Exclusion criteria:}

1. Neuromuscular disorders and brain diseases.

2. Any medical illness rather than controlled T2DM.

3. Temporomandibular joint disorder.

4. Participant with parafunctional oral habits.

\section{Prosthetic procedures:}

Patient examination was done, including extraoral and intraoral examination, panoramic radiograph, and diagnostic casts. 
All patients received finished upper and lower conventional PMMA partial dentures, all required corrections were adjusted as it may affect the records, and they were instructed to maintain satisfactory oral hygiene measures.

Then maximum bite force was measured one day after delivery, one month and two months later.

Then, all patients received flexible partial dentures that fabricated following conventional clinical steps and processed using injection molding technique. Thermoplastic resin (Bre-flex, pink color, bredent, Germany) was cured using thermopress 400 injection molding unit at temperature $260 \mathrm{C}$ and at pressure 5 bar for 26 minutes. After RPD processing, sprues and small flashes were removed carefully and partial dentures were finished and polished using acrylic polishers. RPDs were delivered to the patients and all necessary adjustments were accomplished. All participants were educated and instructed to maintain adequate oral hygiene.

After that, maximum bite force was measured one day after delivery, one month and 2 months later.

\section{Measurements of maximum bite force:}

A portable occlusal force gauge (GM10, Nagano Keiki, Tokyo, Japan) was used to measurethe maximum bite force in the first molar area. Occlusal force gauge comprised of a hydraulic pressure gauge and element for biting that made up of a vinyl material inside a polyethylene tube. The value of bite force was displayed digitally in Newton (N).Its width is $17 \mathrm{~mm}$, height is $5.4 \mathrm{~mm}$ and length is $63.5 \mathrm{~mm}^{(21-23)}$.

The specifications of the device are force range $(0-1000) \mathrm{N}$, accuracy $( \pm 1) \mathrm{N}$, weight about $70 \mathrm{~g}$ and size $195(\mathrm{~L}) \times$ $29(\mathrm{~W}) \times 18(\mathrm{H}) \mathrm{mm}$.

Before recording the maximum bite force, patient was seated in upright position. The device was placed between the upper and lower artificial teeth and the patient was instructed to bite as hard as possible on the biting element of the gauge. Records were taken three times with resting time 30 second between each record and the mean of these three readings is the maximum bite force (MBF).

Records were taken one day after delivery, one month and two months later.

\section{Results:-}

Data were presented as mean \&standard deviation. Statistical analysis was performed with SPSS 16 ( (Statistical Package for Scientific Studies), Graph pad prism \& windows excel.

Independent t-test was performed between two dentures in each record, while comparison between different records separately was performed by One Way Repeated ANOVA, followed by Tukey`s post hok test for multiple comparisons as presented in table (1) \& fig (1).

Comparison between two dentures by independent t-test revealed that MBF for thermoplastic denture was significantly higher than PMMA denture $(\mathrm{P}<0.05)$ as in PMMA denture it was $(27.2 \pm 3.8,30.6 \pm 4.04,35.4 \pm 4.7)$ while in thermoplastic denture it was $(55.4 \pm 5.9,60.2 \pm 4.1 \& 67.6 \pm 5.1)$ after delivery, one month and 2 months later respectively, as presented in table (1), fig (1).

One Way Repetitive ANOVA was performed in each group to compare between three records and revealed significant difference between them $(\mathrm{P}<0.05)$, followed by Tukey`s post hok test for multiple comparisons which revealed significant difference between 3 records in both dentures (Means with different superscript letters were significantly different $\mathrm{P}<0.05$ ) as presented in table (1)

Table 1:- Maximum biting forces of PMMA denture \&thermoplastic denture:

\begin{tabular}{|l|l|l|l|l|l|l|}
\hline & $\mathrm{N}$ & PMMA denture (1) & \multicolumn{2}{l|}{ thermoplastic denture (2) } & \multirow{2}{*}{ P value } \\
\cline { 3 - 6 } & $\mathrm{M}$ & $\mathrm{SD}$ & $\mathrm{M}$ & $\mathrm{SD}$ & \\
\hline At delivery & 30 & $27.2^{\mathbf{a}}$ & 3.83 & $55.4^{\mathbf{a}}$ & 5.94 & $0.001^{*}$ \\
\hline $\begin{array}{l}\text { One month } \\
\text { after delivery }\end{array}$ & 30 & $30.6^{\mathbf{b}}$ & 4.04 & $60.2^{\mathbf{b}}$ & 4.147 & $0.001^{*}$ \\
\hline Two month & 30 & $35.4^{\mathbf{c}}$ & 4.77 & $67.6^{\mathbf{c}}$ & 5.177 & $0.001^{*}$ \\
\hline
\end{tabular}




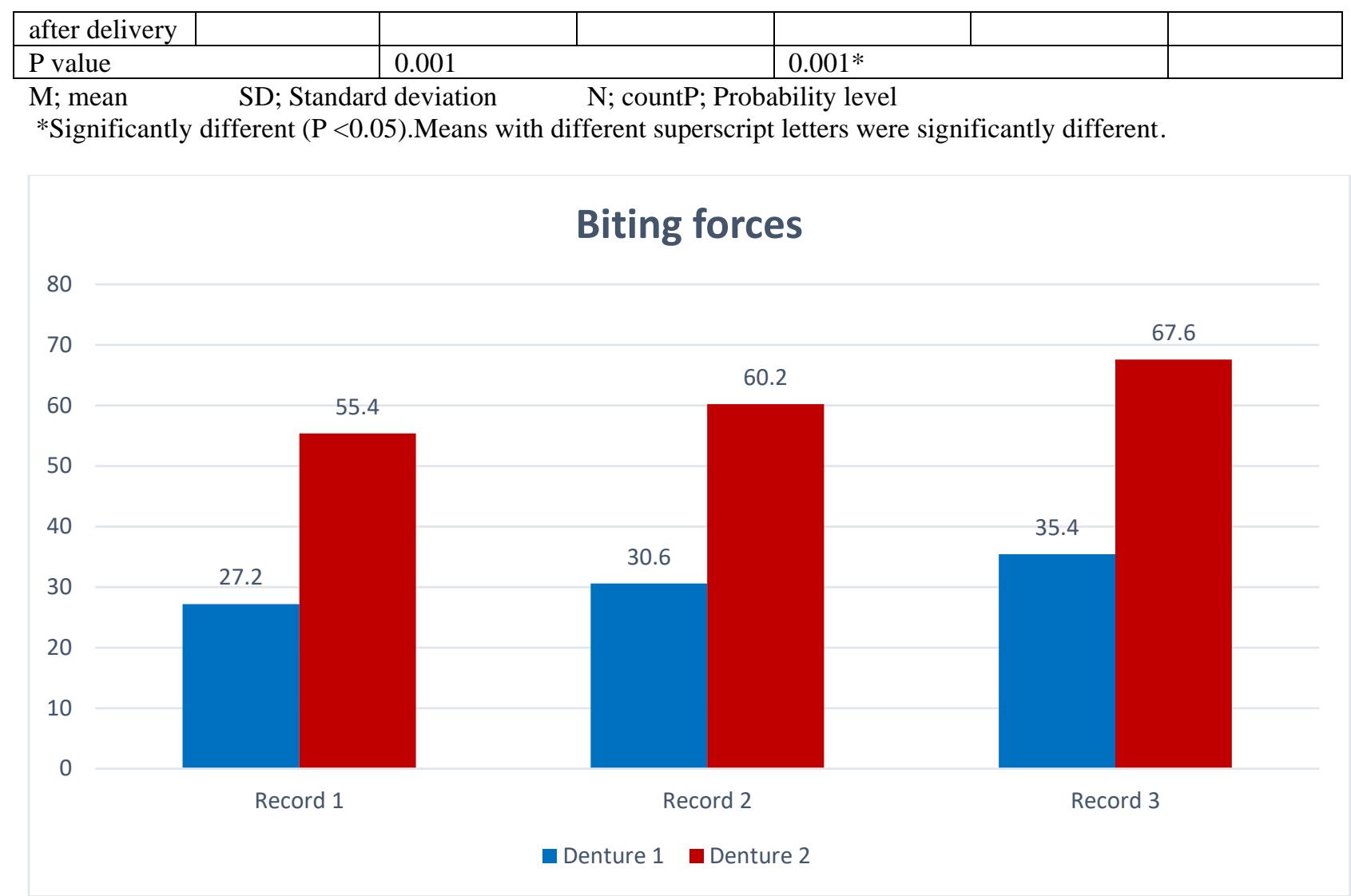

Fig 1:- Bar chart represents biting forces of both dentures at different record intervals.

\section{Discussion:-}

Patients with controlled type $2 \mathrm{DM}$ were selected in the study due to the increased prevalence of DM, as $\sim 140$ million individuals had been reported. Only the controlled diabetic patients were comprised in the study, to maintain blood glucose level nearly close to the normal level because uncontrolled DM showed increasing evidence of chronic oral complications such as caries, periodontitis, oral infections, oral mucosa diseases, teeth loss and faster rate of bone resorption. The more teeth loss, the more MBF reduction ${ }^{(24) .}$

This randomized cross over study was designated to increase accuracy of the statistical results and it is suitable for the variable pattern of teeth loss and the consequentlythe design of RPD. The cross over design is done for a relatively short follow up period to avoid the possible influence of long time period on residual ridge (such as resorption) and the retention of thermoplastic clasps ${ }^{(25,26) .}$

The occlusal force gauge has some advantages: simple, easy to use, has a small thickness, does not restrict with the tongue, soft biting element that enables safe, accurate, and comfortable bite force recording without pain or any discomfort experienced by patients during biting, immediate measurement, and easily sterilized by removing the disposable plastic cover ${ }^{(27)}$.

Many studies had reported that replacement of the missing posterior tooth with RPDs markedly improved the masticatory performance, however all of their starting point for data recording was obtained from partially edentulous conditionjust before the wearing RPDs. The resultspropose that biting ability after RPDs wearingincreased but does not reach the dentulous side. This finding may be attributed to increased activity of muscles of mastication and masticatory performance. Despite, the study subjects hadbounded posterior edentulous area with only $2-4$ missing teeth ${ }^{(28,29)}$

The flexible partial dentures recorded higher MBF than PMMA acrylic partial dentures and the differences between themwas significant $(\mathrm{p}<0.05)$. Flexible denture base materials were providing equal stress distribution and stress 
breaking action that may be attributed to their slight sliding as a result of their inherent flexibility that might allow sufficient normal blood circulation underneath the denture, and therefore, they might reduce the oral soft tissue atrophies $^{(30)}$.

The values of MBF gradually increase as time passesin relation to the initial measurements and this is good indicator of better adaptation to the new partial dentures ${ }^{(31)}$.

\section{Conclusion:-}

Within the limitations of this study, we can conclude that the MBF for restoration of Class III Kennedy classification against Class III Kennedy classification for controlled diabetic patient increased with both RPDs and the increase with flexible removable partial denture was higher than with PMMA partial denture for and MBF increased as the adaptation periods increased.

\section{References:-}

1. Fontijn-Tekamp FA, SlagterAP, Van Der Bilt A.2000. Biting and chewing in overdentures, full dentures, and natural dentitions. Journal of Dental Research, 79(7), 1519-1524.

2. Shinkal RS, Hatch JP, Sakai S. 2001. Oral function and diet quality in a community based sample. Journal of Dental Research, 80, 1625-1630.

3. Miyaura K, Morita M, Matsuka Y, Yamashita A, Watanabe T. 2000Rehabilitation of biting abilities in patients with different types of dental prostheses. Journal of Oral Rehabilitation, 27, 1073-1076.

4. Parle D, Desai D, Bansal A. 2013. Estimation of individual bite force during normal occlusion using FEA. Altair Technol Journal. Infosys, India11-19.

5. Awad GD, Ausama A.2013 Relationship of maximum bite force with craniofacial morphology, body mass and height in an Iraqi adult with different types of malocclusion. J Baghdad Coll Dent. 25(1):129-138.

6. Kogawa EM, Calderon PS, Lauris JR, Araujo CR, Conti PC. 2006 Evaluation of maximal bite force in temporomandibular disorders patients. J Oral Rehabil;33(8):559-65.

7. Koc D, Dogan A, Bek B. 2010Bite force and influential factors on bite force measurements: a literature review. Eur J Dent.; 4(2):223).

8. Fernandes CP, Glantz P-OJ, Svensson SA, Bergmark A. 2003A novel sensor for bite force determinations. Dent Mater;19(2):118-26).

9. Könönen M, Klemetti E, Waltimo A, Ahlberg J, Evälahti M, Kleemola-Kujala E, et al. 2006 Tooth wear in maxillary anterior teeth from 14 to 23 years of age. ActaOdontol Scand.;64(1):55-58.

10. Braun S, Bantleon HP, Hnat WP, Freudenthaler JW, Marcotte MR, Johnson BE. 1995 A study of bite force, part 1: Relationship to various physical characteristics. Angle Orthod; 65(5):367-72.

11. VermaTP et al. 2017 Bite Force Recording Devices - A Review. Journal of Clinical and Diagnostic Research. 11(9): ZE01-ZE05

12. SuwalP et al. 2017 Body Mass Index and maximum bite force in Nepalese population. J DentSpecialities; 5(2):95-97.

13. Jagger RG, Milward PJ, Jagger DC, Vowles RW. 2003Accuracy of adaptation of thermoformed polymethylmethacrylate. J Oral Rehabil; 30(4):364-8.

14. Anusavice KJ. 2012.12th edition Philadelphia WB Saunders 'Phillips. Science of Dental Materials, 238.

15. Lowe LG. 2004 Flexible denture flanges for patients exhibiting undercut tuberosities and reduced width of the buccal vestibule: a clinical report. J Prosthet Dent;92(2):128-31.

16. Vivek R. 2016 Polyamides as a Denture Base Material - A Review. Journal of Dental and Medical Sciences; 15 (12): $119-121$.

17. Prashanti E, Jain N, Shenoy VK, Reddy JM, Shetty B T, Saldanha S. 2010 Flexible dentures: A flexible option to treat edentulous patients. Journal of Nepal Dental Association (2010), Vol. 11, No. 1, Jan.-Jun., 85-87

18. Hamanaka I, Takahashi Y, Shimizu H. 2011 Mechanical properties of injection-molded thermoplastic denture base resins. ActaOdontolScand; 69(2):75-9.

19. Varon F, Shipman M. 2000 the role of dental professional in diabetes care. J ContempDent Prac; 1:1-27.

20. Kansal G, Goyal D. 2013 Prosthodontic Management of Patients with Diabetes Mellitus. J Adv Med Dent Scie Res; 1(1):38-44.

21. He T, Stavropoulos D, Hagberg C, Hakeberg M, Mohlin B.2013 Effects of masticatory muscle training on maximum bite force and muscular endurance. ActaOdontol Scand.; 71(3-4):863-69. 
22. Serra CM, Manns AE. 2013 Bite force measurements with hard and soft bite surfaces. J Oral Rehabil; 40(8):563-68.

23. Varga S, Spalj S, Varga ML, Milosevic SA, Mestrovic S, Slaj M. 2011 Maximum voluntary molar bite force in subjects with normal occlusion. Eur J Orthod.; 33(4):427-33).

24. Abiko Y, Selimovic D. 2010 the mechanism of protracted wound healing on oral mucosa in diabetes: Review. Bosn J Basic Med Sci; 10:186-91.

25. Osada H, Shimpo H, Hayakawa T, Ohkubo C. 2013 Influence of thickness and undercut of thermoplastic resin clasps on retentive force, Dent. Mater J., 32(3), 381-389.

26. Tumrasvin W, FuekiK, Ohyama T. 2006 Factors associated with masticatory performance in unilateral distal extension removable partial denture patients, J. Prosthodont., 15(1), 25-31).

27. Alhaija ES, Al Zo'ubi IA, Al Rousan ME, Mohammad M,Hammad MM. 2009Maximum occlusal biteforces in Jordanian individuals with different dentofacial vertical skeletal patterns. European Journal of Orthodontics (32) $71-77$

28. Tumrasvin $\mathrm{W}$ et al. 2005 Masticatory function after unilateral distal extension removable partial denturetreatment: intra-individual comparison with opposite dentulous side. J Med Dent Sci.; 52: 35-41.

29. Singh SK. 2015 Masticatory efficiency of partially edentulous patient's pre and post fixed prosthodontic rehabilitation. JNDA; 15: 18-23.

30. Ibraheem EM, Hammad HG. 2019 Effect of Commercially Available Denture Adhesives on Microhardness of a Flexible Denture Base Material. Open Access Maced J Med Sci.; 7(5):862-868.

31. Shala K, Tmava-Dragusha A, Dula L, Pustina-Krasniqi T, Bicaj T, Ahmedi E, Lila Z.2018Evaluation of Maximum Bite Force in Patients with Complete Dentures. Open Access Maced J Med Sci.; 6(3): 559-563. 